\title{
Transport, Motility, Biofilm Forming Potential and Survival of Bacillus subtilis Exposed to Cold Temperature and Freeze-Thaw
}

Revised and resubmitted to:

Water Research

February 25, 2014

BAHAREH ASADISHAD ${ }^{a}$, ADAM L. J. OLSSONª, DEVENDRA H. DUSANE ${ }^{a}$, SUBHASIS GHOSHAL $^{\mathrm{b}}$, and NATHALIE TUFENKJI ${ }^{*}$ a

${ }^{a}$ Department of Chemical Engineering, McGill University, Montreal, Quebec H3A 2B2, Canada

bDepartment of Civil Engineering, McGill University, Montreal, Quebec H3A 2K6, Canada

*Corresponding Author. Phone: (514) 398-2999; Fax: (514) 398-6678; E-mail: nathalie.tufenkji@mcgill.ca 


\begin{abstract}
In cold climate regions, microorganisms in upper layers of soil are subject to low temperatures and repeated freeze-thaw (FT) conditions during the winter. We studied the effects of cold temperature and FT cycles on the viability and survival strategies (namely motility and biofilm formation) of the common soil bacterium and model pathogen Bacillus subtilis. We also examined the effect of FT on the transport behavior of $B$. subtilis at two solution ionic strengths (IS: 10 and $100 \mathrm{mM}$ ) in quartz sand packed columns. Finally, to study the mechanical properties of the bacteria-surface bond, a quartz crystal microbalance with dissipation monitoring (QCM-D) was used to monitor changes in bond stiffness when $B$. subtilis attached to a quartz substrate (model sand surface) under different environmental conditions. We observed that increasing the number of FT cycles decreased bacterial viability and that B. subtilis survived for longer time periods in higher IS solution. FT treatment decreased bacterial swimming motility and the transcription of flagellin encoding genes. Although FT exposure had no significant effect on the bacterial growth rate, it substantially decreased B. subtilis biofilm formation and correspondingly decreased the transcription of matrix production genes in higher IS solution. As demonstrated with QCM-D, the bond stiffness between B. subtilis and the quartz surface decreased after FT. Moreover, column transport studies showed higher bacterial retention onto sand grains after exposure to FT. This investigation demonstrates how temperature variations around the freezing point in upper layers of soil can influence key bacterial properties and behavior, including survival and subsequent transport.
\end{abstract}

Keywords: Bacillus subtilis, survival, transport, biofilm formation, motility, bond stiffness 


\section{Introduction}

Microorganisms in upper layers of soil experience frequent changes in environmental conditions, the most notable being temperature fluctuations (Budde et al., 2006). Bacteria in near-surface soil likely experience extreme temperature conditions during the course of a day and seasonal changes, especially in cold climate regions, will subject them to freeze-thaw (FT) conditions (Walker et al., 2006; Yergeau and Kowalchuk, 2008). Bacteria present in soils or biosolids applied to soils can become re-suspended under saturated conditions such as spring melt, potentially reaching groundwater aquifers (Adhikari et al., 2007; Stoddard et al., 1998). The contamination of groundwater supplies by bacterial pathogens can pose a high risk to public health (Curriero et al., 2001; Rose, 1997). Thus, it is important to investigate how cold temperature and FT might affect bacterial survival and transport in natural subsurface environments.

Bacillus subtilis is a Gram positive soil bacterium that is commonly found in the upper layers of soil (Vlamakis et al., 2013). B. subtilis is a good model organism for the study of the transport behavior of Gram positive pathogenic bacteria due to its ease of cultivation, non-pathogenic nature, accessible genetic profile and agricultural relevance (Jiang et al., 2005; Vlamakis et al., 2013). B. subtilis has been used as a surrogate for bacterial pathogens in drinking water supplies in several studies (Greenberg et al., 2010; Pang et al., 2005; Sinclair et al., 2012). In particular, B. subtilis spores have been used as an indicator of Cryptosporidium parvum transport in engineered and riverbank filtration systems (Stimson et al., 2009). B. subtilis has also been

widely accepted as a non-lethal surrogate for $B$. anthracis, the causative agent of anthrax (Nicholson and Galeano, 2003). Cold temperature can substantially influence the transcriptional profiles of B. subtilis as well as its survival and transport behavior (Budde et al., 2006; Jiang et 
al., 2005; Neale and Chapman, 1970). For instance, growth at $15^{\circ} \mathrm{C}$ profoundly alters the physiology of B. subtilis in comparison to cells grown at $37^{\circ} \mathrm{C}$ (Budde et al., 2006; Neale and Chapman, 1970).

B. subtilis employs different strategies and mechanisms to withstand adverse environmental conditions which are crucial for bacterial survival; most notably, motility, matrix production, and the general stress response (Hoffmann and Bremer, 2011; Klein et al., 1999; Lopez et al., 2009). Changes in fatty acid branching pattern in membrane lipids have been reported as an adaptation response for $B$. subtilis to survive cold shock from 37 to $15^{\circ} \mathrm{C}$ (Klein et al., 1999). In another study, this cold shock response in B. subtilis has been characterized by rapid induction and accumulation of stress proteins (Beckering et al., 2002). The flagellum is essential for active movement of bacteria in an aqueous environment and for chemotaxis and plays an important role in interaction with surfaces (Senesi et al., 2004). Biofilms are surface-associated microbial communities that provide constituent cells with some shelter, protecting them from adverse conditions (Davey and O'Toole, 2000). However, studies on the influences of cold temperature and FT on these response strategies are scarce in the literature (Beal et al., 2001; Kato et al., 2002; Yamamoto and Harris, 2001).

In this study, we investigate the role of cold temperature and FT on the survival and transport of $B$. subtilis. The cells were subjected to constant cold temperature $\left(10^{\circ} \mathrm{C}\right)$ or several FT cycles at two solution ionic strengths $(10$ and $100 \mathrm{mM})$ and their survival strategies (e.g., motility and biofilm formation) were monitored. The temperature range chosen was $10^{\circ} \mathrm{C}$ to $-10^{\circ} \mathrm{C}$, a representative temperature profile in upper layers of soil (Burn and Smith, 1988; Zhang et al., 2005) that is experienced over a 10-day period near the end of winter in southern Canada Viability and culturability of the cells along with other physical properties such as cell size and 
cell surface (zeta) potential were investigated before and after FT treatment. The adhesion properties and transport of bacteria exposed to FT were studied using quartz crystal microbalance with dissipation monitoring (QCM-D) and water saturated sand-packed columns, respectively. The expression levels of selected genes encoding proteins related to motility and adhesins were measured using quantitative reverse transcription polymerase chain reaction (qRTPCR).

\section{Materials and Methods}

\subsection{Strains and Culture Conditions}

A Gram positive, non-pathogenic strain of B. subtilis, ATCC 6633A, was used as the test bacterium. Details on cell incubation and harvesting are provided in the Supporting Information. The cells were suspended in 10 or $100 \mathrm{mM} \mathrm{KCl}$ solution without nutrients $(\mathrm{pH} 5.7 \pm 0.1)$ at $10^{9}$ cells/mL. The cell suspension was then maintained at $10^{\circ} \mathrm{C}$ for 16 hours as an acclimatization step to emulate exposure to a cold temperature environment.

\subsection{Freeze-Thaw (FT) Treatment}

After acclimatization, the cell suspension was divided into seven $30 \mathrm{~mL}$ aliquots for different treatments: (1) $\mathrm{Ctrl}$, no further temperature treatment - cells were used at $10^{\circ} \mathrm{C}$ immediately following acclimatization, (2) $5 \mathrm{~d}$ FT, cells exposed to 5 days of FT cycling, (3) $10 \mathrm{~d}$ FT, cells exposed to 10 days of FT cycling, (4 and 5) $5 \mathrm{~d} \mathrm{KCl}$ and $10 \mathrm{~d} \mathrm{KCl}$, cells stored at constant temperature of $10^{\circ} \mathrm{C}$ in $100 \mathrm{mM} \mathrm{KCl}$ for 5 and 10 days, respectively (reference samples with no FT), and (6 and 7) $5 \mathrm{~d} \mathrm{LB}$ and $10 \mathrm{~d} \mathrm{LB}$, cells stored at constant $10^{\circ} \mathrm{C}$ temperature in $\mathrm{LB}$ for 5 and 10 days, respectively (reference samples with no starvation). Samples stored at constant $10^{\circ} \mathrm{C}$ in $\mathrm{KCl}$ or in LB for 5 and 10 days allow for the evaluation of the contribution of FT and starvation 
to bacterial properties, respectively. The FT cycles consisted of consecutive, four 8-hour stages of: a constant temperature at $10^{\circ} \mathrm{C}$, a gradual decrease from $10^{\circ} \mathrm{C}$ to $-10^{\circ} \mathrm{C}$ (at a constant rate of $2.5^{\circ} \mathrm{C} / \mathrm{h}$ ), a constant temperature at $-10^{\circ} \mathrm{C}$ followed by a gradual increase from $-10^{\circ} \mathrm{C}$ to $10^{\circ} \mathrm{C}$ (at $2.5^{\circ} \mathrm{C} / \mathrm{h}$ ). More details on FT treatment and on cell characterization are included in the Supporting Information.

\subsection{Motility and Biofilm Assays and Quantitative Reverse Transcription PCR (qRT- PCR)}

Bacterial swimming and swarming motilities were evaluated for each experimental treatment. Biofilm formation was examined with the standard microtitre plate model. Quantitative Reverse Transcription PCR (qRT-PCR) was used to measure the expression of genes implicated in motility and biofilm formation. Details regarding the experimental methods are provided in the Supporting Information.

\subsection{Quartz Crystal Microbalance with Dissipation Monitoring (QCM-D)}

QCM-D (E4, Q-Sense AB) was employed to investigate the mechanical properties of the bonds between bacteria and a model silica surface. The central component of the QCM-D is the quartz crystal sensor that senses any mass depositing on its surface through shifts in its resonance frequencies $(\Delta f)$ (fundamental and, up to the $13^{\text {th }}$, odd overtones) and dissipation factors $(\Delta D)$ (i.e. dissipative energy losses measured through oscillation decay time). Details on the QCM-D experiments and interpretation of QCM-D data are included in the Supporting Information.

\subsection{Bacterial Transport Experiments}


Transport studies were conducted using an adjustable length glass column of $1 \mathrm{~cm}$ inner diameter (GE Life Sciences) packed with quartz sand. Details regarding the experimental methods are provided in the Supporting Information.

\section{Results and Discussion}

\subsection{Effect of FT on Bacterial Survival}

Viability and culturability of bacteria were measured for $\mathrm{Ctrl}$ (cells acclimatized at $10^{\circ} \mathrm{C}$ for $16 \mathrm{~h}$ with no exposure to FT) and for cells exposed to 5 and $10 \mathrm{~d}$ FT using BacLight Live/Dead and CFU assays, respectively. As presented in Table 1, the culturability of the cells significantly decreased from $2 \times 10^{9} \mathrm{CFU} / \mathrm{mL}$ for Ctrl to 200 and $1 \mathrm{CFU} / \mathrm{mL}$ after 5 and $10 \mathrm{~d}$ FT in $10 \mathrm{mM}$ $\mathrm{KCl}$, respectively. In $100 \mathrm{mM} \mathrm{KCl}$, the plate counts yielded $8.7 \times 10^{4}$ and $6.7 \times 10^{2} \mathrm{CFU} / \mathrm{mL}$ after 5 and $10 \mathrm{~d}$ FT, respectively. The Live/Dead assay results showed $100 \%$ and $30 \%$ reduction in viability after $10 \mathrm{~d}$ FT in 10 and $100 \mathrm{mM} \mathrm{KCl,} \mathrm{respectively} \mathrm{(Table} \mathrm{1).} \mathrm{Freezing} \mathrm{temperatures}$ have been previously reported to markedly affect bacterial cell membrane integrity, allowing leakage of cellular material and influencing cell viability (Calcott and MacLeod, 1975; Kato et al., 2002; Walker et al., 2006; Yamamoto and Harris, 2001). It is suggested that membranes are primarily damaged when cells are frozen and thawed (Mazur, 1966) and viability and membrane damage can be correlated (Calcott and MacLeod, 1975). Herein, the BacLight Live/Dead results confirmed the loss in membrane integrity after FT treatment. The reduction in viability and culturability was more significant in lower IS $(\mathrm{p}<0.05)$. Low cell viability at low IS can be related to high osmotic pressure and electrolyte imbalance across the cell membrane (Record Jr et al., 1998). This result was in agreement with our previous study on Yersinia enterocolitica, 
where bacterial survival decreased when increasing the number of FT cycles (Asadishad et al., 2013).

\subsection{Effect of FT on Bacterial Survival Strategies}

We studied the effect of cold temperature and FT treatment on two B. subtilis survival strategies, motility and biofilm formation, which contribute to the transport of bacteria to a surface, their initial adhesion onto a surface, and matrix production.

\subsubsection{Swimming Motility and Flagellin Expression}

To examine the influence of FT treatment on bacterial motility, the swimming migration of B. subtilis was measured for cells suspended in $100 \mathrm{mM} \mathrm{KCl}$. The higher IS condition was used for these measurements because bacteria were found to be more viable following FT treatment at the higher $\mathrm{KCl}$ concentration (Table 1). Evaluation of swimming motility revealed that FT treatment reduced bacterial motility by approximately $61 \%$ and $89 \%$ after 5 and $10 \mathrm{~d}$, respectively (Figure 1a). Swimming motility of reference samples $5 \mathrm{~d} \mathrm{KCl}$ and $5 \mathrm{~d}$ LB was less repressed $(\sim 35 \%)$ indicating that FT had a more significant effect on motility than the cold temperature treatment $\left(10^{\circ} \mathrm{C}\right)$ and starvation $(\mathrm{p}<0.05)$, respectively. However, for 10-day temperature treatments, the motility impairment was in the same range for reference samples maintained in $\mathrm{LB}$ or $\mathrm{KCl}$ and FT-treated samples.

The flagellum is essential for bacterial movement and plays an important role in bacterial interaction with surfaces (Branda et al., 2004). Several genes are responsible for activity and growth of the flagellum in B. subtilis (Bardy et al., 2003). The hag gene, required for swimming motility, encodes the flagellar filament structural protein flagellin (Mirel and Chamberlin, 1989) and $f l i G$ gene encodes the flagellar motor switch (Blair et al., 2008). 
The effect of FT on the transcription of flagellum and motor switch encoding genes was investigated using qRT-PCR. The transcription of two flagellar genes, hag and fliG, was measured after acclimation at $10^{\circ} \mathrm{C}$, after additional exposure to $10^{\circ} \mathrm{C}$ in $\mathrm{KCl}$ and $\mathrm{LB}$ media, and after FT treatment. The data are presented as the fold change in mRNA expression relative to the expression under control condition (Ctrl) in Figure 1b. In qualitative agreement with the swimming motility measurements, the transcription values for the hag gene decreased after FT treatment. The relative transcription of hag gene was reduced by $35 \%$ and $80 \%$ after 5 and $10 \mathrm{~d}$ FT treatments, respectively (Figure $1 \mathrm{~b}$ ). For $5 \mathrm{~d} \mathrm{LB}$ or $\mathrm{KCl}$, although there was an increase in hag gene transcription, significant decrease in the corresponding swimming motility was observed $(\mathrm{p}<0.05)$. This reduction could be due to the fact that motility is energy intensive (Bardy et al., 2003); and bacteria appeared to be less motile at low temperatures likely in an effort to save energy for their essential metabolic activities. Comparison of $10 \mathrm{~d} \mathrm{LB}$ or $\mathrm{KCl}$ with the 10-day freeze-thawed samples revealed that the flagellin transcription was more decreased after FT treatment ( $\mathrm{p}<0.05$ for $h a g$ ). For the $f l i G$ gene, there was no reduction observed under all conditions except for $5 \mathrm{~d} \mathrm{LB}$ or $\mathrm{KCl}$ and $10 \mathrm{~d}$ FT where the transcription values decreased to less than 50\% compared to Ctrl. This could be another contributing factor to the observed decreased motility for $5 \mathrm{~d} \mathrm{LB}$ or $\mathrm{KCl}$. Overall, the results showed that the FT treatment had a greater effect on the transcription of $h a g$ gene compared to the $f l i G$ gene.

\subsubsection{Swarming Motility and Surfactin and SwrA Expression}

It has been reported that unlike the wild type, the laboratory strains of B. subtilis do not swarm (Patrick and Kearns, 2009). Herein, evaluation of swarming motility revealed that $B$. subtilis minimally swarmed under all conditions and FT treatment had no effect on bacterial swarming motility. Swarming motility requires other genetic features such as surfactant 
production to reduce surface tension and an increase in flagellar number per cell (Patrick and Kearns, 2009). Surfactin, a lipopeptide surfactant produced by B. subtilis, increases surface wettability and facilitates sliding (Abushady et al., 2005). The $s f p$ gene is involved in surfactin production (Ghelardi et al., 2012). SwrA is also essential for swarming motility in B. subtilis (Calvio et al., 2005). It activates flagellar biosynthesis gene expression and increases the number of flagella on the cell surface (Ghelardi et al., 2012).

The effect of FT on the transcription of surfactin and SwrA encoding genes was investigated. The transcription levels of $s f p$ and $s w r A$ were measured before (or without) exposure to FT and after FT treatment. In Figure 1c, the data are presented as the fold change in mRNA expression relative to the expression under control condition (Ctrl). Although no change in swarming motility was observed, the normalized mRNA relative values for $s f p$ gene increased for all conditions except for $10 \mathrm{~d} \mathrm{KCl}$ and $10 \mathrm{~d}$ FT. For example, the relative transcription of $s f p$ gene increased by 2 -fold after $5 \mathrm{~d}$ FT treatment which was significantly higher compared to $5 \mathrm{~d} \mathrm{KCl}$ $(\mathrm{p}<0.05)$ (Figure 1c). In contrast, the transcription of $s w r A$ was decreased by $80 \%$ and $60 \%$ after 5 and $10 \mathrm{~d}$ FT treatments, respectively (Figure 1c). Expression of both $s f p$ and $s w r A$ genes are necessary for swarming motility (Ghelardi et al., 2012). In Ctrl (cells acclimatized at $10^{\circ} \mathrm{C}$ ), the swarming migration of the bacteria was at the same level as the temperature-treated cells (reference conditions in $\mathrm{LB}$ or $\mathrm{KCl}$ and $\mathrm{FT}$ samples) suggesting that even before exposure to FT, the transcription level of $s w r A$ and $s f p$ might not be high enough for bacteria to produce sufficient amount of surfactin or increase the number of flagella for swarming. 

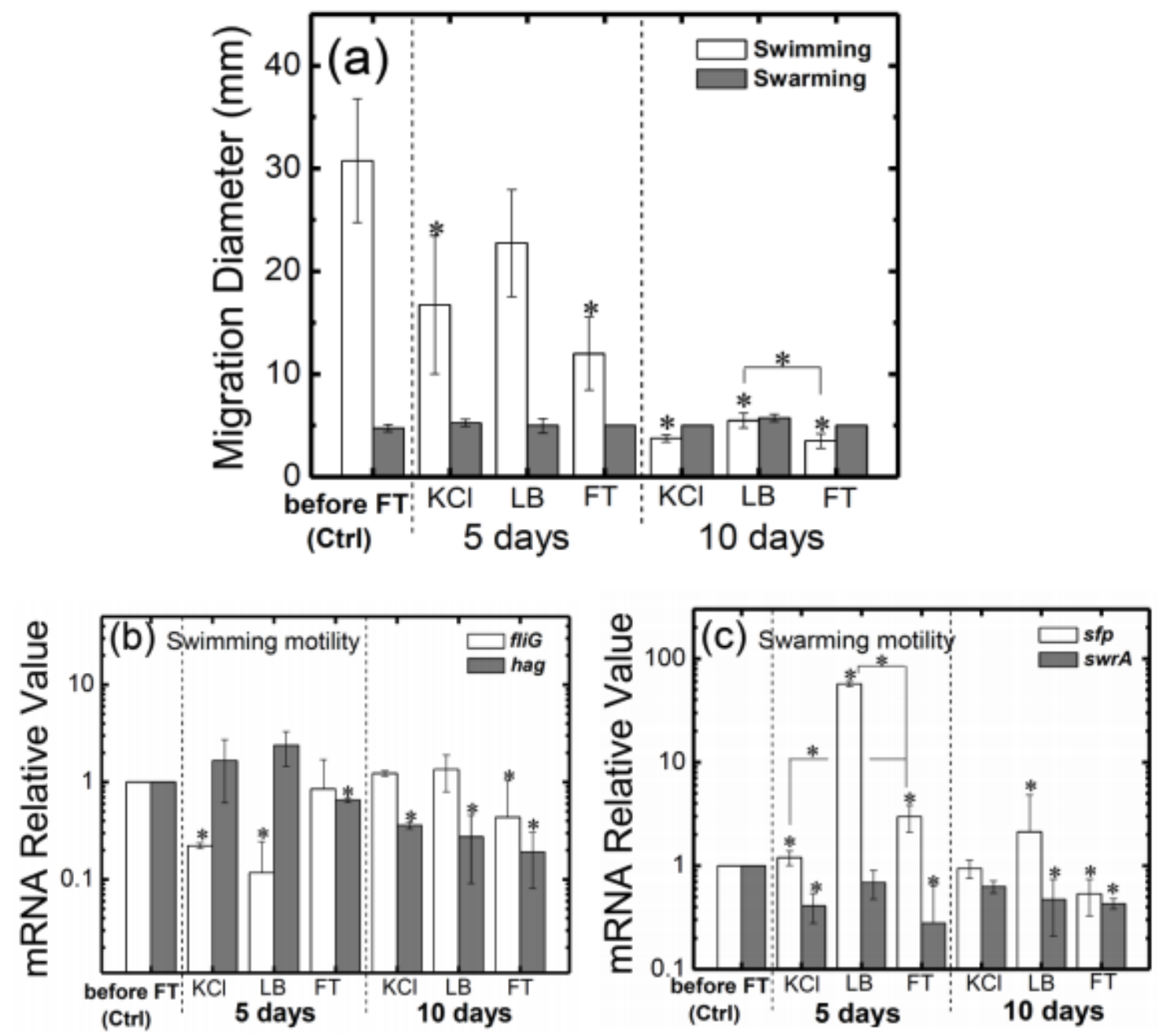

Fig. 1. (a) Characterization of the effects of constant cold temperature $\left(10^{\circ} \mathrm{C}\right)$ and $\mathrm{FT}$ on the swimming and swarming motility of $B$. subtilis in $100 \mathrm{mM} \mathrm{KCl}$. (b-c) Relative mRNA expression of (b) the flagellin encoding genes, fliG and hag, and (c) the surfactin and SwrA encoding genes, $s f p$ and $s w r A$, for B. subtilis before and after FT in $100 \mathrm{mM} \mathrm{KCl}$. Relative mRNA expression of genes was first normalized to that of a housekeeping gene, $r p o B$, and then related to the normalized expression level of the same gene in Ctrl (with no exposure to FT). Results represent mean values \pm SD for three independent experiments. Symbols above a bar indicate a statistically significant difference in measured values when compared to Ctrl (determined using Student's t-test, ${ }^{*}: \mathrm{p}<0.05$ ). Symbols are also used to verify significance of differences between FT and reference conditions ( $5 \mathrm{~d}$ and $10 \mathrm{~d} \mathrm{KCl}$ or LB). 


\subsubsection{Biofilm Formation and Extracellular Matrix Production}

We studied the effect of cold temperature and FT on B. subtilis biofilm formation. Although the bacterial growth remained above $80 \%$ of that of Ctrl, the biofilm formation was substantially decreased after 10 d FT $(\mathrm{p}<0.05)$ (Figure 2a). As shown in Figure 2a, the biofilm formation decreased to $66 \%$ and $3 \%$ of the Ctrl after 5 and $10 \mathrm{~d}$ FT, respectively.

B. subtilis modulates biofilm formation using a number of secreted compounds, one of which is the lipopeptide, surfactin (Cosmina et al., 1993). A mutant with deletion in a surfactin synthase gene deficient in surfactin production failed to form robust biofilm (Shank and Kolter, 2011). As discussed above, surfactin production did not stop after temperature treatment and except for 10 d FT, there was a general increase in $s f p$ gene expression. Thus, other factors must be involved in the observed decreased biofilm formation after FT treatment.

Biofilms of B. subtilis consist of chains of cells that are held together predominately by an extracellular matrix of exopolysaccharide (EPS) and the protein TasA (Branda et al., 2006). EPS is produced by enzymes encoded by the eps A-O operon and the gene encoding Tas A is located in the $y q x M(\operatorname{tap} \mathrm{A})-\operatorname{sip} W$-tasA operon (Serrano et al., 1999). Another extracellular polymer, $\gamma$ polyglutamic acid, has been shown to play a role in cellular adherence to solid surfaces (Budde

et al., 2006). The genes responsible for the synthesis of $\gamma$-polyglutamic acid are pgs $B C A$ (Branda et al., 2006).

In this study, the effect of FT on the transcription of EPS and TasA protein (epsE, tasA) as well as a $\gamma$-polyglutamic acid encoding gene, $\operatorname{pgs} B$, was measured before (or without) exposure to FT and after FT treatment. The results show that there was an 11-fold increase in epsE transcription level after $5 \mathrm{~d}$ FT whereas after $10 \mathrm{~d}$ FT, the relative transcription of epsE gene was substantially decreased to $<1 \%$ (Figure 2b). This is in agreement with the biofilm results which 
showed very low biofilm formation for cells after $10 \mathrm{~d}$ FT (Figure 2a). For $5 \mathrm{~d}$ and $10 \mathrm{~d}$ reference samples in $\mathrm{LB}$ or $\mathrm{KCl}$, the epsE expression was also in qualitative agreement with the observed biofilm formation. In these experiments, tasA transcription levels exhibited 1.1-fold and 2.3-fold increase after 5 and $10 \mathrm{~d}$ FT, respectively (Figure 2c). These results show that a longer period under freezing and thawing conditions had significant effect in reduction of EPS whereas the production of TasA protein increased. It has been reported that the absence of TasA protein or EPS can result in lack of robust biofilm while the absence of both components can cause failure in biofilm formation (Branda et al., 2006). Here, we observed significant reduction in epsE transcription after $10 \mathrm{~d}$ FT treatment which likely contributed to the lack of robust biofilm.

In Figure 2d, the relative transcription of $p g s B$ gene showed no reduction after FT treatment. $p g s B$ expression increased by 12 -fold and 2 -fold after 5 and $10 \mathrm{~d}$ FT, respectively. $p g s B$ is involved in synthesis of $\gamma$-polyglutamic acid which has been reported to function as a cryoprotectant (Bhat et al., 2013). It should be noted that $\gamma$-polyglutamic acid does not contribute significantly to the extracellular matrix (Lopez et al., 2009). 

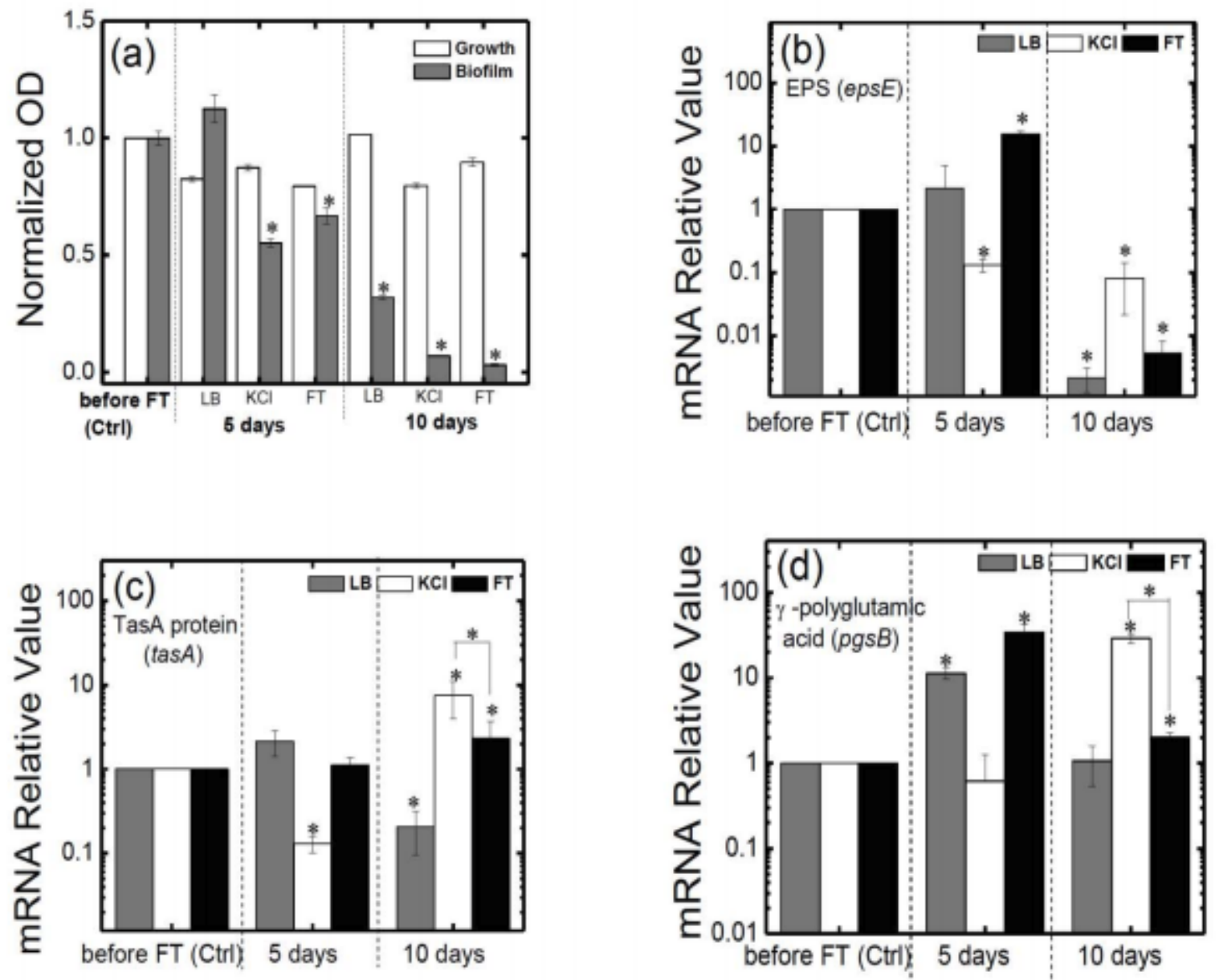

Fig. 2. (a) Characterization of the effects of freeze-thaw on B. subtilis biofilms and planktonic growth in microtitre plate wells at $24 \mathrm{~h}$. Normalized OD $=\left[\mathrm{OD}-\mathrm{OD}_{\text {blank }}\right] /\left[\mathrm{OD}_{\mathrm{Ctrl}}-\mathrm{OD}_{\text {blank }}\right]$. (b-d) Expression levels of genes responsible for the production of extracellular matrix. Relative mRNA expression of (b) exopolysaccharide gene, epsE, (c) TasA protein, $\operatorname{tas} A$, and (d) $\gamma$ polyglutamic acid via pgs $B$ for $B$. subtilis before and after FT in $100 \mathrm{mM} \mathrm{KCl}$. Relative mRNA expression of genes was first normalized to that of a housekeeping gene, $r p o B$, and then related to the normalized expression level of the same gene in Ctrl (with no exposure to FT). Results represent mean values \pm SD for three independent experiments. Symbols above a bar indicate a statistically significant difference in measured values when compared to Ctrl (determined using Student's t-test, *: $\mathrm{p}<0.05$ ). Symbols are also used to verify significance of differences between FT and reference conditions ( $5 \mathrm{~d}$ and $10 \mathrm{~d} \mathrm{KCl}$ or $\mathrm{LB}$ ). 


\subsection{Effect of FT on Mechanical Properties of the Bacterial Bond with the Surface using QCM-D}

To better understand the effect of FT on the adhesive bond strength between attached $B$. subtilis cells and the silica surface, QCM-D experiments were conducted with Ctrl cells (acclimatized at $10^{\circ} \mathrm{C}$ ) and cells exposed to $5 \mathrm{~d}$ and $10 \mathrm{~d}$ FT in two solution ISs. Figure 3a-b presents the frequency and dissipation shifts of the third overtone as a function of time for $B$. subtilis adhering to silica coated QCM-D surfaces, before and after FT, while suspended in 10 and $100 \mathrm{mM} \mathrm{KCl}$. The increase in IS resulted in larger frequency and dissipation shifts indicating more bacterial deposition, which is expected based on compression of the electrical double layer (Tufenkji, 2006). For both IS, FT treatment resulted in larger frequency and dissipation shifts, which is in agreement with higher bacterial retention observed for B. subtilis in the column experiments, as described in section 3.4 below. The median bacterial number densities at the surface were $5.4 \times 10^{5}, 4.2 \times 10^{5}$ and $6 \times 10^{5}$ cells $\mathrm{cm}^{-2}$ at $10 \mathrm{mM} \mathrm{KCl}$ for before FT, $5 \mathrm{~d} \mathrm{FT}$, and $10 \mathrm{~d}$ FT, respectively, and increased to $9.6 \times 10^{5}$ and $8.4 \times 10^{5}$ cells $\mathrm{cm}^{-2}$ at $100 \mathrm{mM} \mathrm{KCl}$ for before FT and 5d FT, respectively. For the treatment of $10 \mathrm{~d}$ FT in $100 \mathrm{mM} \mathrm{KCl}$, cell aggregates were observed on the crystals and therefore, reliable estimates of bacteria counts could not be obtained.

The measured negative frequency shifts (Figure 3a-b) indicate that for B. subtilis deposition onto silica, the QCM-D response was mainly dominated by the bacteria's inertia, and not by deformation of their bond to the surface (Olsson et al., 2012b). In this case, a decrease in bond stiffness would increase the magnitude of the negative frequency shift per individual bacterium, (Olsson et al., 2012a). In Figure 3c, the frequency shifts were divided by the median bacterial number density at the surface for each temperature treatment. In both ISs, the negative frequency 
shift per attached cell increased after FT. If the mass of individual bacteria is assumed to be the same before and after FT, then these results suggest that the stiffness of the bacterial bond to the surface decreased after exposure to FT.

Bond stiffness has been linked to the strength of the bond (Olsson et al., 2012b), and thus, possibly to the bacteria's ability to withstand sheer induced detachment forces. Hence, from these QCM-D results, we hypothesize that even if B. subtilis became "stickier" with FT (as demonstrated in the column experiments, see section 3.4 below), its bond with the surface was weakened, which might enhance the risk of bacterial detachment from the surface when subjected to a liquid flow. This observation, along with the significant reduction in EPS production, might also explain the lack of robust biofilm formation under FT conditions. 

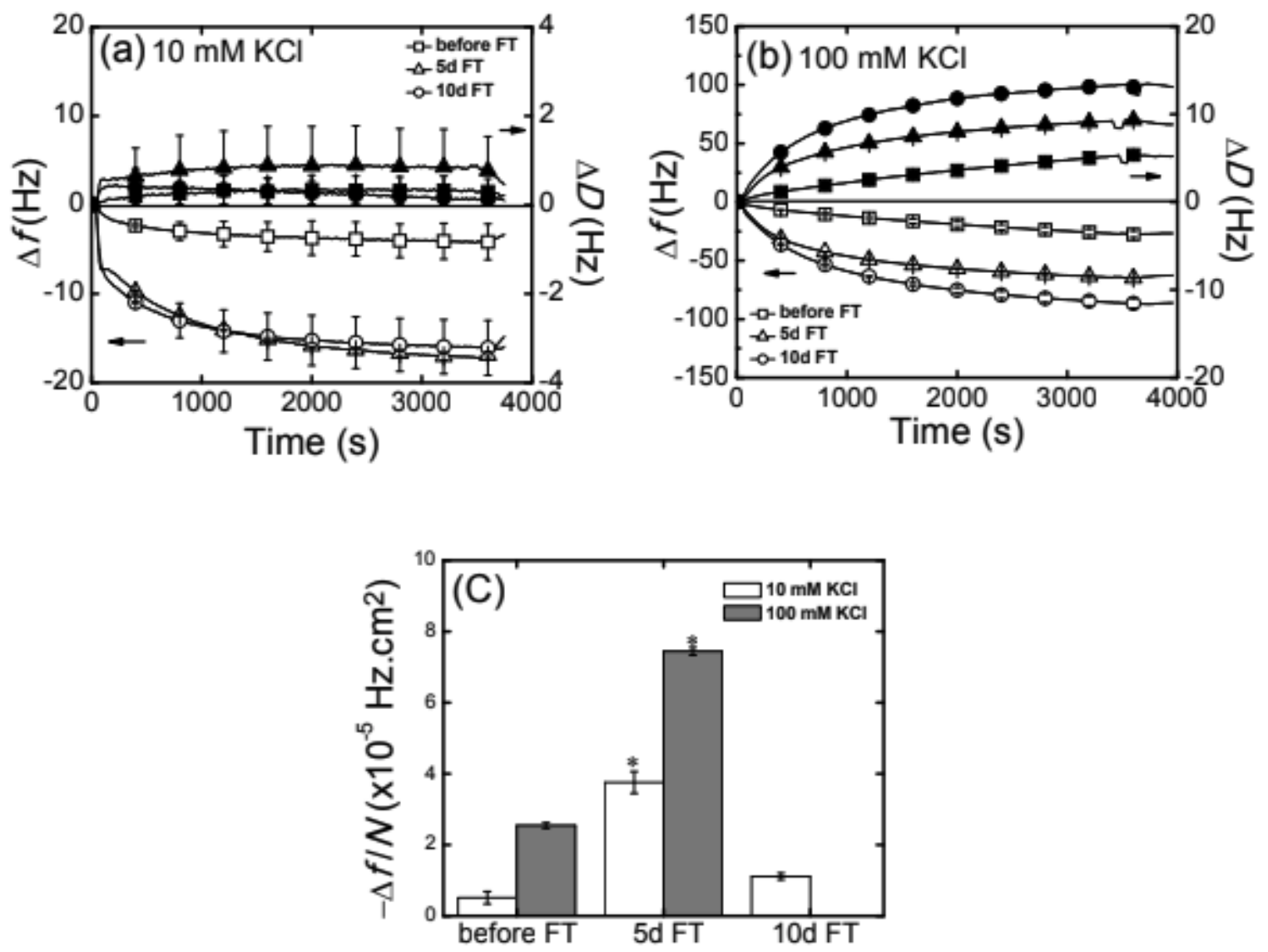

Fig. 3. Effect of FT on bacterial adhesion properties using QCM-D. (a-b) Frequency (open symbols) and dissipation (solid symbols) shifts at $3^{\text {rd }}$ overtone for $B$. subtilis in (a) $10 \mathrm{mM} \mathrm{KCl}$ and (b) $100 \mathrm{mM} \mathrm{KCl}$ before FT and after $5 \mathrm{~d}$ and $10 \mathrm{~d} \mathrm{FT}$. The results are the average of two experiments. (c) Normalized frequency shift $(\Delta f / N)$ at $3^{\text {rd }}$ overtone for B. subtilis in 10 and 100 $\mathrm{mM} \mathrm{KCl}$ before FT treatment and after $5 \mathrm{~d} \mathrm{FT}$. $N$ : represents the number density of the deposited bacteria at the surface determined by fluorescence microscopy and ImageJ software. Because of the presence of cell aggregates on the crystal for $10 \mathrm{~d}$ FT in $100 \mathrm{mM} \mathrm{KCl}$, the $N$ could not be obtained for that condition. Results represent mean values \pm SD for two independent experiments. Symbol above a bar indicate a statistically significant difference in measured values when compared to Ctrl (before FT) (determined using Student's t-test, *: p $<0.05$ ). 


\subsection{Effect of FT on Bacterial Transport}

The transport behavior of bacteria was studied for Ctrl (cells acclimatized at $10^{\circ} \mathrm{C}$ ) and for cells exposed to 5 and $10 \mathrm{~d}$ FT. As shown in Figure 4a, b, increasing the number of FT cycles resulted in higher bacterial retention onto sand grains compared to cells not exposed to FT. The extent of cell retention was greater at higher IS. For example, the percentage of bacterial retention $\left(1-C / C_{0}\right)$ was $5 \%$ and $16 \%$ for the control cells $(\mathrm{Ctrl})$ in 10 and $100 \mathrm{mM} \mathrm{KCl}$, respectively (Figure 4). Here, $C / C_{0}$ is evaluated by numerically integrating the area under the breakthrough curves (BTCs). The percentage of bacterial retention increased to $42 \%$ and $37 \%$ after $10 \mathrm{~d}$ FT in 10 and $100 \mathrm{mM} \mathrm{KCl}$, respectively. Figure 4 also shows cell viability in samples of column effluent suspensions taken at different time points during the transport experiments. Overall, cell viability remained in the same range $( \pm 10 \%)$ during transport of the cell suspension in the sand indicating that there was no difference in the deposition behavior of live versus damaged cells. The greater extent of bacterial retention after FT treatment may be related to changes in the physicochemical properties of the cells such as surface charge, size, motility, and molecular composition of the cell wall (Abu-Lail and Camesano, 2003; Haznedaroglu et al., 2008; Kjelleberg and Hermansson, 1984; McCaulou et al., 1995; Tufenkji, 2007). 

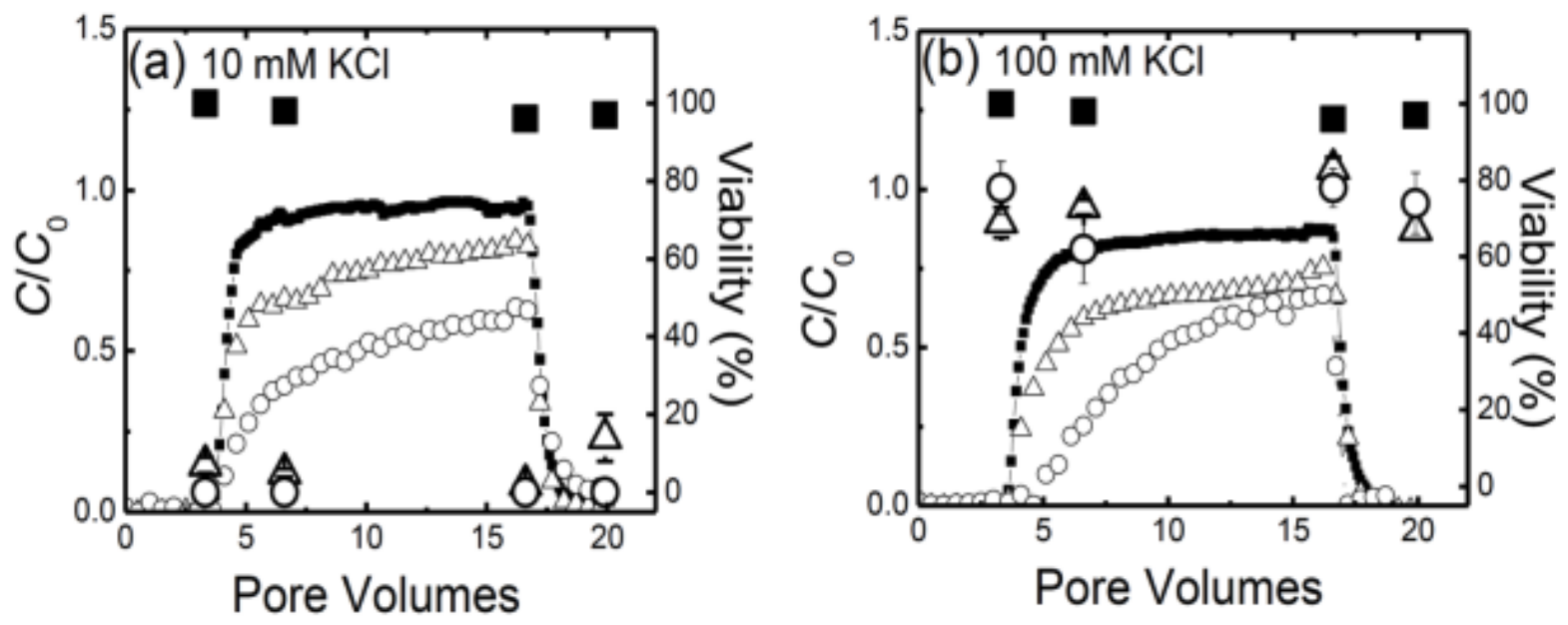

Fig. 4. Breakthrough curves (BTC) for transport of B. subtilis through clean quartz sand at $10^{\circ} \mathrm{C}$

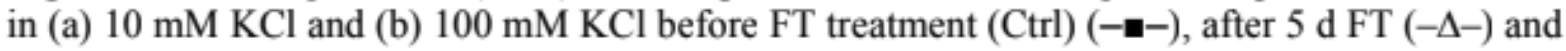
after $10 \mathrm{~d}$ FT (-O-). BTCs were identical for two replicate experiments. The viability of cells in the column effluent at different time points was measured using the Live/Dead assay and the results are also included on the graphs: Ctrl (घ), after $5 \mathrm{~d}$ FT $(\Delta)$ and after $10 \mathrm{~d}$ FT (o). The error bars indicate the standard deviation.

The bacterial surface (zeta) potentials were evaluated from EPM measurements conducted over the range of experimental conditions and are presented in Table 1. The results indicate that bacteria were negatively charged in both IS at $\mathrm{pH}$ 5.7. The absolute magnitude of the cell zeta potential decreased with an increase in IS of $\mathrm{KCl}$, as expected based on compression of the electrical double layer (Tufenkji, 2006) resulting in greater bacterial retention onto sand grains in higher IS. Zeta potentials of clean sand are also negative at these conditions $(\sim-30 \mathrm{mV}$ and $\sim-5$ $\mathrm{mV}$ for 10 and $100 \mathrm{mM} \mathrm{KCl,} \mathrm{respectively)} \mathrm{at} \mathrm{pH}$ 5.7, as reported elsewhere (Tufenkji et al., 2004). In both IS, the absolute zeta potential decreased after 5 d FT but increased to values higher than its initial value $(\sim-20 \mathrm{mV})$ after $10 \mathrm{~d}$ FT. This variation in cell surface charge could be due to secretion of EPS and cryoproteins. If classical DLVO (Derjaguin and Landau, Verwey and Overbeek) interactions were controlling the bacterial transport behavior, we would expect the cells exposed to $5 \mathrm{~d}$ FT to exhibit higher retention than the $10 \mathrm{~d}$ FT cells; however, inspection 
of Figure 4 reveals that this is not the case. Thus, bacterial zeta potential data suggest that factors other than electrostatic forces were involved in controlling the transport behavior of FT-treated B. subtilis.

The hydrodynamic diameters of the cells were measured by DLS. The cell size did not change much through FT treatments, with hydrodynamic diameters of $1 \pm 0.1 \mu \mathrm{m}$ before exposure to FT (Ctrl) and $0.9 \pm 0.02 \mu \mathrm{m}$ after $10 \mathrm{~d}$ FT in $100 \mathrm{mM} \mathrm{KCl}$ under the no nutrient condition (Table 1). These results suggest that cell size did not contribute to higher bacterial retention observed following FT. In higher IS, the cell size reduced to $0.5 \mu \mathrm{m}$ after $5 \mathrm{~d}$ FT but the cells regained their original size $(\sim 1 \mu \mathrm{m})$ after $10 \mathrm{~d}$ FT. This size reduction after $5 \mathrm{~d}$ FT could contribute to the observed increased bacterial deposition (as much as 16\%) due to increased Brownian diffusion of the smaller cells compared to the cells that were not exposed to FT (Ctrl).

The motility of the bacteria was measured as described above. A reduction in bacterial swimming motility was observed after exposure to FT (Figure 1a). Some studies report greater attachment of motile bacteria compared to their non-motile counterparts (Becker et al., 2004; Camper et al., 1993; Kerchove and Elimelech, 2008). However, the opposite has also been shown (Camesano and Logan, 1998). Herein, we observed a coincidence between decreased bacterial motility after FT treatment and higher bacterial retention onto sand (Figure 4).

Table 1. Characterization of $B$. subtilis cells before and after freeze-thaw (FT) treatment in 10 and $100 \mathrm{mM} \mathrm{KCl}$ (pH 5.7). Results represent mean values $\pm \mathrm{SD}$ for three independent experiments.

\begin{tabular}{|c|c|c|c|c|c|c|c|c|}
\hline \multirow[b]{2}{*}{$\mathrm{KCl}(\mathrm{mM})$} & \multicolumn{2}{|c|}{ Culturability (CFU/mL) } & \multicolumn{2}{|c|}{ Viability (\%) } & \multicolumn{2}{|c|}{ Cel diameter ( $(\mu \mathrm{m})$} & \multicolumn{2}{|c|}{ Zeta potential (mV) } \\
\hline & 10 & 100 & 10 & 100 & 10 & 100 & 10 & 100 \\
\hline before FT (Ctrl) & $2.0 \times 10^{9} \pm 0.0$ & $8.3 \times 10^{8} \pm 4.2 \times 10^{8}$ & $100 \pm 0$ & $100 \pm 0$ & $1.7 \pm 0.2$ & $1.0 \pm 0.1$ & $-27.9 \pm 0.5$ & $-21.6 \pm 0.4$ \\
\hline after $5 \mathrm{~d}$ FT & $200.0 \pm 18.9$ & $8.7 \times 10^{4} \pm 2.3 \times 10^{4}$ & $7 \pm 2$ & $78 \pm 7$ & $0.9 \pm 0.0$ & $0.5 \pm 0.0$ & $-15.8 \pm 0.6$ & $-14.7 \pm 1.8$ \\
\hline after 10d FT & $1.0 \pm 0.0$ & $6.7 \times 10^{2} \pm 1.4 \times 10^{2}$ & $0 \pm 0$ & $69 \pm 4$ & $0.8 \pm 0.1$ & $0.9 \pm 0.0$ & $-36.9 \pm 0.4$ & $-29.9 \pm 0.8$ \\
\hline
\end{tabular}




\section{Conclusions}

This study shows how temperature variations around freezing point in upper layers of soil might influence different bacterial properties, as well as bacterial survival and transport behavior, and thus impact the extent of pathogenic contamination of groundwater. Soil is the main habitat

of B. subtilis and therefore, B. subtilis can be subject to cold temperature and seasonal FT processes. B. subtilis has been widely accepted as a representative surrogate for bacterial pathogens, particularly, B. anthracis (Nicholson and Galeano, 2003). Thus, the study of $B$. subtilis fate and transport as a surrogate can help to improve risk assessment and public health protection. The results of this study show that viability of $B$. subtilis decreased after exposure to FT, but bacteria exhibited greater survival when suspended in a higher IS solution. Common survival strategies of $B$. subtilis such as motility and biofilm formation were significantly influenced. Impaired motility and lack of robust biofilm formation were observed after $10 \mathrm{~d}$ of FT treatment. Bacterial transport studies revealed greater bacterial retention onto sand grains after exposure to FT, however, the strength/stiffness of the bacteria-silica bond was found to weaken after FT. Weak bonds between bacteria and the substratum may lead to detachment of cells from surface or near surface soil during spring melt resulting in subsurface transport and risk of bacterial contamination. 


\section{Acknowledgements}

This research was supported by the Canadian Water Network, the Natural Sciences and Engineering Research Council of Canada (NSERC), the McGill Engineering Doctoral Award Program (MEDA), the Canada Research Chairs (CRC) Program and the Fonds québécois de la recherche sur la nature et les technologies (FQRNT).

\section{Appendix A. Supporting Information}

Strain and culture conditions and primers designed for this study and some of the experimental methods. This information can be found at http://dx.doi.org/. 


\section{References}

Abu-Lail, N. I., Camesano, T. A., 2003. Role of lipopolysaccharides in the adhesion, retention, and transport of Escherichia coli JM109. Environmental Science \& Technology 37 (10), 2173-2183.

Abushady, H. M., Bashandy, A. S., Aziz, N. H., Ibrahim, H. M. M., 2005. Molecular characterization of Bacillus subtilis surfactin producing strain and the factors affecting its production. International Journal of Agriculture and Biology 7 (3), 337-344.

Adams, L. H., 1915. The measurement of the freezing-point depression of dilute solutions. Journal of the American Chemical Society 37 (3), 481-496.

Adhikari, H., Barnes, D., Schiewer, S., White, D., 2007. Total coliform survival characteristics in frozen soils. Journal of Environmental Engineering 133 (12), 1098-1105.

Asadishad, B., Ghoshal, S., Tufenkji, N., 2013. Role of Cold Climate and Freeze-Thaw on the Survival, Transport, and Virulence of Yersinia enterocolitica. Environmental Science \& Technology 47 (24), 14169-14177.

Bais, H. P., Fall, R., Vivanco, J. M., 2004. Biocontrol of Bacillus subtilis against infection of Arabidopsis roots by Pseudomonas syringae is facilitated by biofilm formation and surfactin production. Plant Physiology 134 (1), 307-319.

Bardy, S. L., Ng, S. Y. M., Jarrell, K. F., 2003. Prokaryotic motility structures. Microbiology 149 (2), 295-304.

Beal, C., Fonseca, F., Corrieu, G., 2001. Resistance to freezing and frozen storage of Streptococcus thermophilus is related to membrane fatty acid composition. Journal of Dairy Science 84 (11), 2347-2356.

Becker, M. W., Collins, S. A., Metge, D. W., Harvey, R. W., Shapiro, A. M., 2004. Effect of cell physicochemical characteristics and motility on bacterial transport in groundwater. Journal of Contaminant Hydrology 69 (3-4), 195-213.

Beckering, C. L., Steil, L., Weber, M. H. W., Völker, U., Marahiel, M. A., 2002. Genomewide transcriptional analysis of the cold shock response in Bacillus subtilis. Journal of Bacteriology 184 (22), 6395-6402.

Bhat, A., Irorere, V., Bartlett, T., Hill, D., Kedia, G., Morris, M., Charalampopoulos, D., Radecka, I., 2013. Bacillus subtilis natto: a non-toxic source of poly- $\gamma$-glutamic acid that could be used as a cryoprotectant for probiotic bacteria. AMB Express 3 (1), 1-9.

Blair, K. M., Turner, L., Winkelman, J. T., Berg, H. C., Kearns, D. B., 2008. A molecular clutch disables flagella in the Bacillus subtilis biofilm. Science 320 (5883), 1636-1638.

Branda, S. S., Chu, F., Kearns, D. B., Losick, R., Kolter, R., 2006. A major protein component of the Bacillus subtilis biofilm matrix. Molecular Microbiology 59 (4), 1229-1238.

Branda, S. S., González-Pastor, J. E., Dervyn, E., Ehrlich, S. D., Losick, R., Kolter, R., 2004. Genes involved in formation of structured multicellular communities by Bacillus subtilis. Journal of Bacteriology 186 (12), 3970-3979.

Budde, I., Steil, L., Scharf, C., Völker, U., Bremer, E., 2006. Adaptation of Bacillus subtilis to growth at low temperature: a combined transcriptomic and proteomic appraisal. Microbiology 152 (3), 831-853.

Burn, C. R., Smith, C. A. S., 1988. Observations of the "thermal offset" in near-surface mean annual ground temperatures at several sites near Mayo, Yukon territory, Canada. Arctic 41 (2), 99-104.

Calcott, P., MacLeod, R., 1975. The survival of Escherichia coli from freeze-thaw damage: permeability barrier damage and viability. Canadian Journal of Microbiology 21 (11), 1724-32.

Calvio, C., Celandroni, F., Ghelardi, E., Amati, G., Salvetti, S., Ceciliani, F., Galizzi, A., Senesi, S., 2005. Swarming differentiation and swimming motility in Bacillus subtilis are controlled by swrA, a newly identified dicistronic operon. Journal of Bacteriology 187 (15), 5356-5366. 
Camesano, T. A., Logan, B. E., 1998. Influence of fluid velocity and cell concentration on the transport of motile and nonmotile bacteria in porous media. Environmental Science \& Technology 32 (11), 1699-1708.

Camper, A. K., Hayes, J. T., Sturman, P. J., Jones, W. L., Cunningham, A. B., 1993. Effects of motility and adsorption rate coefficient on transport of bacteria through saturated porous media. Applied and Environmental Microbiology 59 (10), 3455-3462.

Castro, F. D., Tufenkji, N., 2007. Relevance of nontoxigenic strains as surrogates for Escherichia coli O157:H7 in groundwater contamination potential: Role of temperature and cell acclimation time. Environmental Science \& Technology 41 (12), 4332-4338.

Chen, G., Walker, S. L., 2007. Role of solution chemistry and ion valence on the adhesion kinetics of groundwater and marine bacteria. Langmuir 23 (13), 7162-7169.

Cosmina, P., Rodriguez, F., de Ferra, F., Grandi, G., Perego, M., Venema, G., van Sinderen, D., 1993. Sequence and analysis of the genetic locus responsible for surfactin synthesis in Bacillus subtilis. Molecular Microbiology 8 (5), 821-831.

Curriero, F. C., Patz, J. A., Rose, J. B., Lele, S., 2001. The association between extreme precipitation and waterborne disease outbreaks in the United States, 1948-1994. American Journal of Public Health 91 (8), 1194-1199.

Davey, M. E., O'Toole, G. A., 2000. Microbial biofilms: from ecology to molecular genetics. Microbiology and Molecular Biology Reviews 64 (4), 847-867.

Dybwad, G. L., 1985. A sensitive new method for the determination of adhesive bonding between a particle and a substrate. Journal of Applied Physics 58 (7), 2789-2790.

Earl, A. M., Losick, R., Kolter, R., 2008. Ecology and genomics of Bacillus subtilis. Trends in Microbiology 16 (6), 269-275.

Elimelech, M., Gregory, J., Jia, X., Williams, R. A., 1995. Particle deposition and aggregation: Measurement, modeling and simulation. ButterworthHeinemann: Oxford.

Ghelardi, E., Salvetti, S., Ceragioli, M., Gueye, S. A., Celandroni, F., Senesi, S., 2012. Contribution of surfactin and SwrA to flagellin expression, swimming and surface motility in Bacillus subtilis. Applied and Environmental Microbiology.

Greenberg, D. L., Busch, J. D., Keim, P., Wagner, D. M., 2010. Identifying experimental surrogates for Bacillus anthracis spores: a review. Investigative Genetics 1 (4), 1-12.

Haznedaroglu, B. Z., Bolster, C. H., Walker, S. L., 2008. The role of starvation on Escherichia coli adhesion and transport in saturated porous media. Water Research 42 (6-7), 1547-1554.

Hoffmann, T., Bremer, E., 2011. Protection of Bacillus subtilis against cold stress via compatible-solute acquisition. Journal of Bacteriology 193 (7), 1552-1562.

Jiang, G., Noonan, M. J., Buchan, G. D., Smith, N., 2005. Transport and deposition of Bacillus subtilis through an intact soil column. Soil Research 43 (6), 695-703.

Junge, K., Eicken, H., Swanson, B. D., Deming, J. W., 2006. Bacterial incorporation of leucine into protein down to $-20^{\circ} \mathrm{C}$ with evidence for potential activity in sub-eutectic saline ice formations. Cryobiology 52 (3), 417-429.

Kato, S., Jenkins, M. B., Fogarty, E. A., Bowman, D. D., 2002. Effects of freeze-thaw events on the viability of Cryptosporidium parvum oocysts in soil. Journal of Parasitology 88 (4), 718-722.

Kerchove, A. J. d., Elimelech, M., 2008. Bacterial swimming motility enhances cell deposition and surface coverage. Environmental Science \& Technology 42 (12), 4371-4377.

Kjelleberg, S., Hermansson, M., 1984. Starvation-induced effects on bacterial surface characteristics. Applied and Environmental Microbiology 48 (3), 497-503.

Klein, W., Weber, M. H. W., Marahiel, M. A., 1999. Cold shock response of Bacillus subtilis: Isoleucinedependent switch in the fatty acid branching pattern for membrane adaptation to low temperatures. Journal of Bacteriology 181 (17), 5341-5349.

Kobayashi, K., 2007. Bacillus subtilis pellicle formation proceeds through genetically defined morphological changes. Journal of Bacteriology 189 (13), 4920-4931. 
Lesage, S., Jackson, R. E., Priddle, M. W., Riemann, P. G., 1990. Occurrence and fate of organic solvent residues in anoxic groundwater at the Gloucester landfill, Canada. Environmental Science \& Technology 24 (4), 559-566.

Lindeberg, G., Lode, A., 1963. Release of ultraviolet-absorbing material from Escherichia coli at subzero temperatures Canadian Journal of Microbiology 9 (4), 523-530.

Lopez, D., Vlamakis, H., Kolter, R., 2009. Generation of multiple cell types in Bacillus subtilis. FEMS Microbiology Reviews 33 (1), 152-163.

Mazur, P., 1966. Theoretical and experimental effects of cooling and warming velocity on the survival of frozen and thawed cells. Cryobiology 2 (4), 181-192.

McCaulou, D. R., Bales, R. C., Arnold, R. G., 1995. Effect of temperature-controlled motility on transport of bacteria and microspheres through saturated sediment. Water Resources Research 31 (2), 271-280.

Mirel, D. B., Chamberlin, M. J., 1989. The Bacillus subtilis flagellin gene (hag) is transcribed by the sigma 28 form of RNA polymerase. Journal of Bacteriology 171 (6), 3095-3101.

Neale, E. K., Chapman, G. B., 1970. Effect of low temperature on the growth and fine structure of Bacillus subtilis. Journal of Bacteriology 104 (1), 518-528.

Nicholson, W. L., Galeano, B., 2003. UV resistance of Bacillus anthracis spores revisited: validation of Bacillus subtilis spores as UV surrogates for spores of B. anthracis sterne. Applied and Environmental Microbiology 69 (2), 1327-1330.

O'Toole, G., Kaplan, H. B., Kolter, R., 2000. Biofilm formation as microbial development. Annual Review of Microbiology 54 (1), 49-79.

Olofsson, A.-C., Hermansson, M., Elwing, H., 2005. Use of a quartz crystal microbalance to investigate the antiadhesive potential of n-acetyl-i-cysteine. Applied and Environmental Microbiology 71 (5), 2705-2712.

Olsson, A. L. J., Sharma, P. K., van der Mei, H. C., Busscher, H. J., 2012a. Adhesive bond stiffness of Staphylococcus aureus with and without proteins that bind to an adsorbed fibronectin film. Applied and Environmental Microbiology 78 (1), 99-102.

Olsson, A. L. J., van der Mei, H. C., Johannsmann, D., Busscher, H. J., Sharma, P. K., 2012b. Probing colloid-substratum contact stiffness by acoustic sensing in a liquid phase. Analytical Chemistry 84 (10), 4504-4512.

Otto, K., Elwing, H., Hermansson, M., 1999. Effect of ionic strength on initial interactions of Escherichia coli with surfaces, studied on-line by a novel quartz crystal microbalance technique. Journal of Bacteriology 181 (17), 5210-5218.

Pang, L., Close, M., Goltz, M., Noonan, M., Sinton, L., 2005. Filtration and transport of Bacillus subtilis spores and the F-RNA phage MS2 in a coarse alluvial gravel aquifer: Implications in the estimation of setback distances. Journal of Contaminant Hydrology 77 (3), 165-194.

Patrick, J. E., Kearns, D. B., 2009. Laboratory strains of Bacillus subtilis do not exhibit swarming motility. Journal of Bacteriology 191 (22), 7129-7133.

Pomorska, A., Shchukin, D., Hammond, R., Cooper, M. A., Grundmeier, G., Johannsmann, D., 2010. Positive frequency shifts observed upon adsorbing micron-sized solid objects to a quartz crystal microbalance from the liquid phase. Analytical Chemistry 82 (6), 2237-2242.

Record Jr, M. T., Courtenay, E. S., Cayley, D. S., Guttman, H. J., 1998. Responses of E. coli to osmotic stress: large changes in amounts of cytoplasmic solutes and water. Trends in biochemical sciences 23 (4), 143-148.

Reviakine, I., Johannsmann, D., Richter, R. P., 2011. Hearing what you cannot see and visualizing what you hear: Interpreting quartz crystal microbalance data from solvated interfaces. Analytical Chemistry 83 (23), 8838-8848.

Rose, J. B., 1997. Environmental ecology of Cryptosporidium and public health implications. Annual Review of Public Health 18 (1), 135-161. 
Senesi, S., Ghelardi, E., Celandroni, F., Salvetti, S., Parisio, E., Galizzi, A., 2004. Surface-associated flagellum formation and swarming differentiation in Bacillus subtilis are controlled by the ifm locus. Journal of Bacteriology 186 (4), 1158-1164.

Serrano, M., Zilhão, R., Ricca, E., Ozin, A. J., Moran, C. P., Henriques, A. O., 1999. A Bacillus subtilis secreted protein with a role in endospore coat assembly and function. Journal of Bacteriology 181 (12), 3632-3643.

Shank, E. A., Kolter, R., 2011. Extracellular signaling and multicellularity in Bacillus subtilis. Current Opinion in Microbiology 14 (6), 741-747.

Sinclair, R. G., Rose, J. B., Hashsham, S. A., Gerba, C. P., Haas, C. N., 2012. Criteria for selection of surrogates used to study the fate and control of pathogens in the environment. Applied and Environmental Microbiology 78 (6), 1969-1977.

Stimson, J., Chik, A., Mesquita, M., McLellan, N., Emelko, M. In Field-scale evaluation of the cotransport impacts of Bacillus subtilis endospores on other pathogen surrogates, AGU Fall Meeting Abstracts, 2009; p 05.

Stoddard, C. S., Coyne, M. S., Grove, J. H., 1998. Fecal bacteria survival and infiltration through a shallow agricultural soil: Timing and tillage effects. Journal of Environmental Quality 27 (6), 1516-1523.

Stöver, A. G., Driks, A., 1999. Secretion, localization, and antibacterial activity of TasA, a Bacillus subtilis spore-associated protein. Journal of Bacteriology 181 (5), 1664-1672.

Tufenkji, N., 2006. Application of a dual deposition mode model to evaluate transport of Escherichia coli D21 in porous media. Water Resources Research 42 (12), W12S11.

Tufenkji, N., 2007. Modeling microbial transport in porous media: Traditional approaches and recent developments. Advances in Water Resources 30 (6-7), 1455-1469.

Tufenkji, N., Miller, G. F., Ryan, J. N., Harvey, R. W., Elimelech, M., 2004. Transport of Cryptosporidium oocysts in porous media: Role of straining and physicochemical filtration. Environmental Science \& Technology 38 (22), 5932-5938.

Vlamakis, H., Chai, Y., Beauregard, P., Losick, R., Kolter, R., 2013. Sticking together: building a biofilm the Bacillus subtilis way. Nature Reviews Microbiology 11 (3), 157-168.

Walker, V. K., Palmer, G. R., Voordouw, G., 2006. Freeze-thaw tolerance and clues to the winter survival of a soil community. Applied and Environmental Microbiology 72 (3), 1784-1792.

Yamamoto, S. A., Harris, L. J., 2001. The effects of freezing and thawing on the survival of Escherichia coli O157:H7 in apple juice. International Journal of Food Microbiology 67 (1-2), 89-96.

Yergeau, E., Kowalchuk, G. A., 2008. Responses of Antarctic soil microbial communities and associated functions to temperature and freeze-thaw cycle frequency. Environmental Microbiology 10 (9), 2223-2235.

Zhang, Y., Chen, W., Smith, S. L., Riseborough, D. W., Cihlar, J., 2005. Soil temperature in Canada during the twentieth century: Complex responses to atmospheric climate change. Journal of Geophysical Research: Atmospheres 110 (D3), D03112. 